\title{
Modeling the sensitivity of outdoor recreation activities to climate change
}

\author{
Robert Finger $^{1, *}$, Niklaus Lehmann ${ }^{2}$ \\ ${ }^{1}$ Agricultural Economics and Rural Policy Group, Wageningen University, Hollandseweg 1, 6706 KN Wageningen, \\ The Netherlands \\ ${ }^{2}$ Agri-Food and Agri-Environmental Economics Group, ETH Zürich, Sonneggstrasse 33, 8092 Zürich, Switzerland
}

\begin{abstract}
This study develops a methodological framework to analyze the climate sensitivity as well as climate change impacts on outdoor recreation activities, applied to a case study of 2 lidos in the city of Zurich. A negative binomial regression is used to link daily data on lido entries with weather variables for the period 2003 to 2010, while controlling for non-climatic factors (such as weekends and school holidays). It shows that the number of lido visitors is significantly determined by weather conditions such as temperature and rainfall. Results from the regressions are combined with output of a stochastic weather generator to fully explore climate risks on a monthly and annual basis under current conditions. This setup is furthermore used to predict near future climate change impacts on lido entries using 3 emission scenarios. It shows that near future climate change characterized by temperature increases and reduced precipitation levels in late summer will have a positive effect on the number of lido visitors. While the expected increase of the annual number of visitors ranges from 9 to $19 \%$, increases of $>30 \%$ are expected for August and September.
\end{abstract}

KEY WORDS: Outdoor recreation - Climate sensitivity - Weather - Climate change impacts · Stochastic weather generator

\section{INTRODUCTION}

Weather conditions are one of the major determinants for leisure, sport, tourist and outdoor recreation activities (Palutikof et al. 2004, Nicholls et al. 2008, Perch-Nielsen 2010). Therefore, the impact of climate on these activities has received particular attention (for overviews see Gössling \& Hall 2006, Nicholls et al. 2008, Perch-Nielsen 2010, Perch-Nielsen et al. 2010). Climate change will, for instance, lead to changes of visitor flows within seasons of the year as well as to changes in the activities used (e.g. PerchNielsen et al. 2010). Climate change is also expected to lead to shifts in visitor flow in a country (Elsasser \& Bürki 2002) as well as on an international level (Hamilton et al. 2005, Perch-Nielsen 2010). Leisure, sport, tourism and outdoor recreation activities are important for regional and national economies. Fur- thermore, these activities are crucial for the wellbeing of societies and are thus of particular economic and societal importance. Quantifying the exposure and sensitivity of these activities to changes in climatic conditions is thus of outmost importance (Perch-Nielsen 2010). Even though the relationships between weather and outdoor recreation are obvious, quantitative assessments of these effects are rare (see e.g. Nicholls et al. 2008 for a literature overview). Existing literature that explicitly links weather with the participation in outdoor recreation activities ranges from the analysis of water-based activities (e.g. Berkhout \& Brouwer 2005 for the Netherlands), golfing (e.g. Nicholls et al. 2008 for the USA), skiing (e.g. Koenig \& Abegg 1997 for Switzerland, Moen \& Fredman 2007 for Sweden, Dawson et al. 2009 for the USA, Endler \& Matzarakis 2011 for Germany), leisure time physical (outdoor) activities in general 
(e.g. Eisenberg \& Okeke 2009 for the USA) to the visiting of national parks (e.g. Richardson \& Loomis 2005 for the USA). These studies show that weather has a large effect on outdoor recreation. However, other variables such as weekends or official holidays as well as economic determinants (e.g. gas and entry prices) and the socioeconomic status of people (e.g. income and education) were also found to significantly affect outdoor recreation activities.

Building on this background, we investigated the climate sensitivity of outdoor recreation activities using the example of 2 lidos in the city of Zurich, Switzerland. Swimming is one of the most popular sports in Zurich with a total annual visitor number in public lidos and swimming baths of $>2$ million. Thus, these leisure and sport activities play an important role from a social and economic perspective and are 'an integral part of urban culture' in Zurich.

This study develops a methodological framework to analyze the climate sensitivity of outdoor recreation activities, which can be also used to project climate change effects. Our goal is to quantify the relationship between weather and lido entries in Zurich using negative binomial regressions. In order to fully explore climate risks on a monthly and annual basis, results from the regressions are combined with output of a stochastic weather generator. This methodical setup is furthermore used to predict near future climate change effects on lido entry patterns.

The analysis is relevant for different interest groups. First of all, empirically founded advice is of particular importance for all stakeholders to quantify weather sensitivities as well as near-future climate change effects, to develop strategies for risk mitigation and adaptation to changes in climate. The specific information provided in this article for lidos at Lake Zurich can, together with similar information on other sites and activities, help policy makers to develop or adjust plans for the provision (and demand) of outdoor recreation activities in the city of Zurich. Furthermore, lido managers may use the information to adjust management with respect to weather sensitivity as well as to adjust mid-term planning.

The proposed combination of regression results with a stochastic weather generator represents a methodological improvement beyond applications on outdoor recreation. Risks in general and climate risks in particular are becoming more and more important for stakeholders and policy makers (e.g. IPCC 2007). The literature on the weather and climate change sensitivity of outdoor recreation activities has not considered this aspect so far. To fill this gap, the proposed methodology provides a new framework for exploring climate risks quantitatively in more detail and precision. It thus provides an important step in the stochastic modeling of weather and climate risks in outdoor recreation.

\section{METHODS}

To quantify the sensitivity of public lido entries to weather conditions, we employ a regression analysis that uses daily entry data of 2 public lidos at Lake Zurich (Switzerland) covering the period 2003-2010. Lido entries are explained with daily weather data of a climate station in the city of Zurich as well as nonclimatic factors. The use of count data (i.e. the number of daily entries) has to be considered if conducting regression analysis, because the ordinary least squares method results in biased, inefficient, and inconsistent estimates in this case (Long 1997). The default choice to analyze such count data are generalized linear models with Poisson distributions (i.e. Poisson models) (see e.g. Land et al. 1996, Long 1997, Greene 2008). Assuming the Poisson model to our data leads, however, to over-dispersion. We thus used a negative binomial model, which is more generally applicable than the Poisson model ${ }^{2}$. This choice was also recommended by a likelihood ratio test for over-dispersion in count data. The negative binomial regression model finally used in our analysis is defined as follows:

$$
E\left[y_{\mathrm{i}} \mid X_{\mathrm{i}}, \varepsilon\right]=\mathrm{e}^{\left(\alpha+\beta X^{\prime}+\varepsilon\right)}
$$

where $E\left[y_{\mathrm{i}} \mid x_{\mathrm{i}}\right]$ is the expected value of the dependent count variable given the specific values for the independent variables $x_{i}$; $\alpha$ and $\beta$ are the regression parameters to be estimated, and $\varepsilon$ is the error term. Relaxing the assumption of the Poisson regression that the conditional mean $\left(\lambda_{\mathrm{i}}\right)$ and the variance of $y_{\mathrm{i}}$ given $x_{i}$ are equal, the variance in the employed negative binomial regression model is defined as $\operatorname{Var}\left(y_{\mathrm{i}} \mid x_{\mathrm{i}}, \varepsilon\right)=\lambda_{\mathrm{i}}+\kappa \lambda_{\mathrm{i}}^{2}$. Method overviews are presented, for instance, in Greene (2008) and Land et al. (1996).

In order to explain the number of daily entries to the lidos, we use several weather variables (or indi-

\footnotetext{
1 City of Zurich (2010) Zürcher Bäderkultur: von der Badestube zur Erlebniswelt, available at: www.sportamt.ch (accessed May 30, 2011). A historical overview on lidos is provided in: City of Zurich (2011) Dokumentation Sportamt, available at: www.sportamt.ch (accessed May 30, 2011).

$\underline{2}$ We also employed a Quasi-Poisson regression model, which led to similar results as the negative Binomial model.
} 
cators derived therefrom) as well as dummy variables that indicate weekends, official holidays and school holidays (see Section 3).

In a subsequent step, the estimated regression models are used to explore the annual and monthly variability of lido entries. To this end, the stochastic weather generator LARS-WG (Semenov \& Barrow 1997, Semenov et al. 1998) is used to simulate 100 annual sets of daily weather data that represent current climatic conditions (BASE scenario). More specifically, LARS-WG was applied to obtain daily weather data for temperature and precipitation. The use of a weather generator was also necessary to downscale the results from a (large scale) climate model to a specific weather station. The weather generator was conditioned using daily weather observations for 1980 to $2009^{3}$. Further details on the application of the weather generator are described in Finger et al. (2010) and Finger \& Calanca (2011). These 100 sets of daily weather data are then combined with the regression coefficients to predict the number of daily lido entries, which are used to calculate averages and standard deviations of entries at annual and monthly levels. To ensure comparability among years, all nonclimatic variables are kept constant (i.e. are set on the observed patterns) for predictions. For instance, the number of holiday and weekend days is identical in all years. Moreover, the analyzed period is kept constant at the average observed time span when the lidos were open (ranging from day of year 126 to $256^{4}$ ) to ensure comparability across years. To account for the maximum capacity of the lidos, predictions that exceed the maximum visitor number observed in the 2003-2010 period are set equal to these maximum values.

This setup, which combines the weather generator with the regression coefficients, is also used to investigate the sensitivity of public lido entries to changes in climatic conditions in the near future. To this end, the weather generator LARS-WG is used to simulate daily weather data under expected climate conditions for the period 2011-2030 (i.e. representing the time slice around 2020). We use climate change scenarios derived from the atmospheric general circulation model (GCM) HadCM3 (see Gordon et al. 2000 for detailed descriptions), considering 3 IPCC emission scenarios. The simulated internal climate variability on an interannual scale of the HadCM3 model

\footnotetext{
$\underline{3}$ Built-in statistical tests of LARS-WG indicate a satisfactorily performance of the stochastic weather generator for this site.

${ }^{4}$ May 06 to September 13, following the dates at the lido Tiefenbrunnen.
}

has amplitudes and patterns that are in overall agreement to the observed variability (Collins et al. 2001).

Although expected changes in the climate change scenarios were derived assuming 1961 to 1990 as a reference period, LARS-WG internally rescales these assumptions to account for the fact that the observational data (i.e. the BASE scenario) covers the period 1980 to 2009 (Finger \& Calanca 2011). Again, 100 sets of daily weather data are derived for each climate scenario and are used to predict lido entries on a daily basis. To ensure comparability, all non-climatic variables were held fixed, as for the simulations for the BASE period.

Following the procedure for the BASE scenario, the daily predictions of lido entries under the climate change scenarios are aggregated at the monthly and annual scale, from which averages and standard deviations are presented. In order to test for differences in mean and variability of lido entries, we employ the Mann-Whitney $U$-test and the AnsariBradley test, respectively.

\section{DATA}

Daily entry data for 2 public lidos at Lake Zurich, Mythenquai and Tiefenbrunnen, are provided by the sports department of the city of Zurich, Switzerland. Daily data on temperature and precipitation for the weather station Zurich Fluntern are provided by the Swiss Federal Office of Meteorology and Climatology. The definitions and summary statistics of the dependent and independent variables are presented in Table 1. Temperature enters the model as a continuous variable. In addition, a dummy variable that indicates heat days is included in the model. Precipitation is not used as a continuous variable in our model due to high correlations with both temperature related variables, which caused multicollinearity and unstable regression models. Instead, we use a dummy variable defining rainy days. Besides the average air temperature on the analyzed day, we include the average temperature of the 10 previous days to approximate general weather conditions and water temperature. Even though water temperature is monitored at Lake Zurich, an organizational change with regard to the responsibility for the monitoring does not allow having a continuous time series over the entire period analyzed here ${ }^{5}$. Not considering

\footnotetext{
${ }^{5}$ No continuous water temperature record was available to the sports department of the City of Zurich (pers. comm).
} 
Table 1. Summary of employed variables for the opening period of the lidos. Square brackets: values for discrete variables

\begin{tabular}{|c|c|c|c|}
\hline Variable & Description & Mean & Range $( \pm \mathrm{SD})$ \\
\hline \multicolumn{4}{|l|}{ Dependent } \\
\hline Tiefenbrunnen entries & For $2003-2010(n=1000)$ & 1306 & $1-12474( \pm 1857)$ \\
\hline Mythenquai entries & For $2003-2010(n=981)$ & 1229 & $1-11702( \pm 1591)$ \\
\hline \multicolumn{4}{|l|}{ Independent } \\
\hline \multicolumn{4}{|l|}{ Time trend (2003-2010) } \\
\hline Weekend dummy & Equals 1 for weekends (Saturday and Sunday) & 0.29 & {$[0,1]$} \\
\hline Official holiday dummy & Equals 1 for official holiday days in Zurich & 0.02 & {$[0,1]$} \\
\hline School holiday dummy & Equals 1 for school holidays in the city of Zurich & 0.27 & {$[0,1]$} \\
\hline $\begin{array}{l}\text { Dummy for the time of } \\
\text { European Championship } 2008\end{array}$ & $\begin{array}{l}\text { Equals } 1 \text { for time of } 2008 \text { UEFA European Football } \\
\text { Championship ( } 7 \text { Jun-29 Jun) }\end{array}$ & 0.02 & {$[0,1]$} \\
\hline \multicolumn{4}{|l|}{ Weather variables } \\
\hline Rainy day dummy & Equals 1 if daily rainfall is $>0 \mathrm{~mm}$ & 0.51 & {$[0,1]$} \\
\hline Hot day dummy & Equals 1 if the daily average temperature exceeds $23^{\circ} \mathrm{C}^{\mathrm{a}}$ & 0.07 & {$[0,1]$} \\
\hline Daily temperature & Daily mean temperature $\left({ }^{\circ} \mathrm{C}\right)$ & 17.55 & $5.1-27.7( \pm 3.95)$ \\
\hline $10 \mathrm{~d}$ average temperature & Mean temperature of 10 previous days $\left({ }^{\circ} \mathrm{C}\right)$ & 17.34 & $8.6-26.5( \pm 3.21)$ \\
\hline
\end{tabular}

water temperature, however, leads to unexplained autocorrelative patterns in regression residuals. Including the $10 \mathrm{~d}$ average temperature as a proxy variable for water temperature ${ }^{6}$ removed these autocorrelation patterns from the regression residuals. In addition to climatic variables, we use information if a specific day was a weekend day, an official holiday, coincided with school holidays or with the 2008 UEFA European Football Championship (7 June 2008 to 29 June 2008) that took place in Zurich (and other cities). In order to capture trends over time in the entry data that cannot be explicitly captured by the variables (e.g. changing preferences of visitors, income and population growth), we include an annual time trend in the regressions.

Table 2 summarizes the climate change scenarios with respect to changes in temperature and precipitation employed in our analysis. The scenarios that represent the period 2011 to 2030 (i.e. the time slice around 2020) are taken from the HadCM3 model (e.g. Pope et al. 2000) using the emissions Scenarios A1B, A2 and B1 (Nakicenovic et al. 2000). Table 2 shows that Scenario A1B assumes the most distinct temperature increases and decreases of precipitation, while Scenario B1 represents moderate changes in near-future climate. For all 3 scenarios, the ex-

\footnotetext{
${ }^{6}$ Different proxy variables were employed, all leading to qualitatively similar results. The $10 \mathrm{~d}$ average temperature was chosen because it showed the best potential to remove autocorrelation patterns.
}

pected temperature increases and precipitation decreases (except for Scenario A2 in September) are particularly large forAugust and September.

\section{RESULTS}

Coefficient estimates of the negative binomial regressions are presented in Table 3. Note that exponentials of coefficient estimates are presented. Thus, these coefficient estimates can be interpreted as multiplicative changes in the response variable (number of entries) for a one unit change in the respective explanatory variable.

The time trend coefficient shows that the annual increase of visitors (taking weather, holiday and other effects into account) is $4 \%$ for the Tiefenbrun-

Table 2. Summary of climate change scenarios A1B, A2, B1. Changes $(\Delta)$ in monthly climate statistics between 2011-2030 (predictions) and 1961-1990. Prec: monthly precipitation; Temp: daily air temperature

\begin{tabular}{|c|c|c|c|c|c|c|}
\hline & $\begin{array}{c}\mathrm{A} 1 \\
\Delta \mathrm{Temp} \\
\left({ }^{\circ} \mathrm{C}\right)\end{array}$ & $\begin{array}{c}\Delta \mathrm{B}- \\
\begin{array}{c}\Delta \%) \\
\text { Prec }\end{array}\end{array}$ & $\begin{array}{c}\mathrm{A} \\
\Delta \mathrm{Temp} \\
\left({ }^{\circ} \mathrm{C}\right)\end{array}$ & $\begin{array}{c}\Delta-2- \\
(\%)\end{array}$ & $\begin{array}{c}-\mathrm{B} \text { Temp } \\
\left({ }^{\circ} \mathrm{C}\right)\end{array}$ & $\begin{array}{c}1 \\
\begin{array}{c}\Delta \text { Prec } \\
(\%)\end{array}\end{array}$ \\
\hline May & 0.61 & -2 & 0.59 & -5 & 0.35 & +5 \\
\hline June & 0.37 & -2 & 0.16 & +2 & 0.24 & -1 \\
\hline July & 0.27 & -2 & 0.05 & +3 & 0.13 & +1 \\
\hline August & 0.94 & -11 & 1.17 & -10 & 0.64 & -5 \\
\hline September & 0.97 & -13 & 0.70 & +5 & 0.58 & -2 \\
\hline
\end{tabular}


Table 3. Coefficient estimates of negative binomial regressions. ${ }^{* *} \mathrm{p}<0.05,{ }^{* * *} \mathrm{p}<0.01, \mathrm{~ns}$ : not significant. AIC: Akaike information criterion

\begin{tabular}{|lcc|}
\hline \multirow{2}{*}{ Variable } & \multicolumn{2}{c|}{ Coefficients $( \pm \mathrm{SE})$} \\
& Tiefenbrunnen & Mythenquai \\
\hline Intercept & $0.76 \pm 0.24, \mathrm{~ns}$ & $0.92 \pm 0.20, \mathrm{~ns}$ \\
Time trend (yr) & $1.04 \pm 0.01^{* *}$ & $1.00 \pm 0.01, \mathrm{~ns}$ \\
Weekend dummy & $2.76 \pm 0.07^{* * *}$ & $1.89 \pm 0.07^{* * *}$ \\
Official holiday dummy & $2.26 \pm 0.23^{* * *}$ & $1.39 \pm 0.19, \mathrm{~ns}$ \\
School holiday dummy & $1.44 \pm 0.08^{* * *}$ & $1.13 \pm 0.07^{* *}$ \\
European Champion- & $0.61 \pm 0.24^{* *}$ & $0.71 \pm 0.22, \mathrm{~ns}$ \\
ship dummy & & \\
Rainy day dummy & $0.45 \pm 0.08^{* * *}$ & $0.43 \pm 0.07^{* * *}$ \\
Hot day dummy & $0.49 \pm 0.15^{* * *}$ & $0.47 \pm 0.13^{* * *}$ \\
Daily temperature & $1.40 \pm 0.01^{* * *}$ & $1.44 \pm 0.01^{* * *}$ \\
10 d mean temperature & $1.04 \pm 0.01^{* *}$ & $1.01 \pm 0.01), \mathrm{ns}$ \\
AIC & 14686 & 14285 \\
& & \\
\hline
\end{tabular}

nen lido. In contrast, no deterministic change of visitor numbers over time has been found for the Mythenquai lido. School holidays lead to $44 \%$ (Tiefenbrunnen) and $13 \%$ (Mythenquai) more visitors. During weekends, between $176 \%$ (Tiefenbrunnen) and $89 \%$ (Mythenquai) more visitors than during the week can be expected. Also official holidays have a significant positive effect on daily entries. The effects of these official holidays on lido entries are again larger for the Tiefenbrunnen lido. These results show that the number of lido entries for the Mythenquai lido tends to be less sensitive to holidays and weekends, suggesting a more constant visitor flow in specific time windows (e.g. within weeks and months). This is also underlined by comparing (absolute and relative) variability of daily entries, which is significantly higher at the Tiefenbrunnen lido compared to the Mythenquai lido (Table 1).

Fewer visitors were observed during the European Football Championship than expected, given the weather conditions. The lake area was used as a fanzone during the European Football Championship, possibly discouraging usual lido visitors.

During a rainy day, a $2.22(1 / 0.45)$ and $2.33(1 / 0.43)$ fold decrease of entries is indicated for Tiefenbrunnen and Mythenquai, respectively. As expected, temperature has a positive effect on the number of visitors: a $1^{\circ} \mathrm{C}$ higher temperature leads to an increase of visitors by $\sim 40$ to $44 \%^{\underline{7}}$. However, too high temperatures have a negative effect: for hot days, a sharp decrease in the number of visitors has to be expected. Alternative leisure and sport activities (e.g.

${ }^{7}$ The interquartile range of daily mean temperature is small $\left(14.9-20.6^{\circ}\right)$, which explains the strong temperature response of the model. in the cooler mountainous regions) may be more attractive at this time ${ }^{8}$. The average temperature of the 10 previous days has a positive effect on the numbers of visitors, though this variable is only significant for the Tiefenbrunnen lido. This variable reflects warm water temperatures and good general weather conditions, and both of them are expected to increase the attractiveness of visiting a lido. In contrast to the non-climatic variables, sensitivities of visitor flows to the weather variables are similar for both lidos, i.e. there are only small differences in the magnitude of estimated coefficients for temperature and rainfall variables. Thus, weather sensitivity of lido visitor flows is robust against the choice of the location and seems to be generally applicable. This is additionally underlined if both lidos are investigated jointly in a single regression model (i.e. the average of visitors from both lidos is used), which leads to coefficient estimates of similar magnitudes and significance levels (not shown).

Table 4 shows the annual and monthly means and the associated standard erros for the BASE as well as for the climate change scenarios, which are derived from the combination of the regression model with the output of the stochastic weather generator (see Methods).

The total number of annual lido visitors increases significantly due to climate change. Depending on the scenario, an increase between $8.75 \%$ (B1) and $18.26 \%(\mathrm{~A} 1 \mathrm{~B})$ is expected for the Tiefenbrunnen lido. For the Mythenquai lido the number of visitors per year increases between 9.16\% (B1) and 18.75\% (A1B). In particular higher temperatures contribute to this development. Note that climate sensitivities are similar in both lidos (Table 3), and thus also climate change responses in visitor flows are in a similar range. Particularly in the beginning and at the end of the lido season, significantly more entries are expected. This is due to the fact that $10 \mathrm{~d}$ average temperatures (as a proxy for general weather conditions and water temperature) during spring are higher in the climate change scenarios. The marked increases of visitors in August and September are particularly caused by reduced rainfall probabilities and higher temperatures (Table 2). Again, the B1 scenario indicates the smallest changes of visitors in August and September (increases of $\sim 14$ to $16 \%$ ), while the A1B and A2 scenarios indicate much larger increases (ranging from 26 to $39 \%$ ). Near-future cli-

\footnotetext{
$\underline{8}$ Higher temperatures still lead to more entries (variable temperature), and thus both coefficients have to be considered jointly.
} 
Table 4. Predicted monthly and annual visitor sums (mean, SD in parentheses) for different climate scenarios (A1B, A2, B1). ${ }^{* *} \mathrm{p}<0.05,{ }^{* * *} \mathrm{p}<0.01$ : significant differences (diff.) in expected number of visitors compared to the BASE scenario (MannWhitney $U$-test). ${ }^{x x} \mathrm{p}<0.05$ : significant differences in dispersion of visitors compared to the BASE scenario (Ansari-Bradley test)

\begin{tabular}{|c|c|c|c|c|c|c|c|}
\hline \multirow[b]{2}{*}{ Tiefenbrunnen } & \multirow[t]{2}{*}{ BASE } & \multirow[t]{2}{*}{$\mathrm{A} 1 \mathrm{~B}$} & $\%$ diff. to BASE & \multirow[t]{2}{*}{ A2 } & $\%$ diff. to BASE & \multirow[t]{2}{*}{ B1 } & $\%$ diff. to BASE \\
\hline & & & & & & & \\
\hline Total year & $\begin{array}{l}161035 \\
(20795)\end{array}$ & $\begin{array}{c}190446^{* * *} \\
(21653)\end{array}$ & +18.26 & $\begin{array}{c}188569 * * * \\
(21475)\end{array}$ & +17.1 & $\begin{array}{c}175123^{* * *} \\
(19799)\end{array}$ & +8.75 \\
\hline May $^{\mathrm{a}}$ & $\begin{array}{c}8003 \\
(2983)\end{array}$ & $\begin{array}{l}9981^{* * *} \\
(2734)^{\mathrm{xx}}\end{array}$ & +24.72 & $\begin{array}{l}9188^{* * *} \\
(2707)^{\mathrm{xx}}\end{array}$ & +14.81 & $\begin{array}{c}9022^{* *} \\
(3098)\end{array}$ & +12.73 \\
\hline June & $\begin{array}{l}24127 \\
(7198)\end{array}$ & $\begin{array}{c}26720^{* *} \\
(7237)\end{array}$ & +10.75 & $\begin{array}{l}25233 \\
(6956)\end{array}$ & +4.58 & $\begin{array}{c}26395^{* *} \\
(7365)\end{array}$ & +9.40 \\
\hline July & $\begin{array}{c}58054 \\
(13478)\end{array}$ & $\begin{array}{c}63387^{* * *} \\
(12178)\end{array}$ & +9.19 & $\begin{array}{c}57039 \\
(12641)\end{array}$ & -1.75 & $\begin{array}{c}58671 \\
(12402)\end{array}$ & +1.06 \\
\hline August & $\begin{array}{c}61258 \\
(12953)\end{array}$ & $\begin{array}{c}77213^{* * *} \\
(14233)\end{array}$ & +26.05 & $\begin{array}{c}84320^{* * *} \\
(15856)\end{array}$ & +37.65 & $\begin{array}{c}69850^{* * *} \\
(14835)\end{array}$ & +14.03 \\
\hline September ${ }^{\mathrm{a}}$ & $\begin{array}{c}9593 \\
(3790)\end{array}$ & $\begin{array}{c}13145^{* * *} \\
(4316)\end{array}$ & +37.03 & $\begin{array}{c}12790^{* * *} \\
(4210)\end{array}$ & +33.33 & $\begin{array}{c}11185^{* * *} \\
(3729)\end{array}$ & +16.60 \\
\hline \multicolumn{8}{|l|}{ Mythenquai } \\
\hline Total year & $\begin{array}{l}141594 \\
(17412)\end{array}$ & $\begin{array}{c}168138^{* * *} \\
(19188)\end{array}$ & +18.75 & $\begin{array}{c}165235^{* * *} \\
(17690)\end{array}$ & +16.70 & $\begin{array}{c}154568^{* * *} \\
(16931)\end{array}$ & +9.16 \\
\hline May $^{\mathrm{a}}$ & $\begin{array}{c}7748 \\
(2841)\end{array}$ & $\begin{array}{l}9719^{* * *} \\
(2596)^{\mathrm{xx}}\end{array}$ & +25.44 & $\begin{array}{l}8901^{* * *} \\
(2546)^{\mathrm{xx}}\end{array}$ & +14.88 & $\begin{array}{c}8828^{* * *} \\
(2994)\end{array}$ & +13.94 \\
\hline June & $\begin{array}{c}24388 \\
(7205)^{*}\end{array}$ & $\begin{array}{c}26916^{*} \\
(7374)\end{array}$ & +10.37 & $\begin{array}{l}25464 \\
(6922)\end{array}$ & +4.41 & $\begin{array}{c}26702^{* *} \\
(7464)\end{array}$ & +9.49 \\
\hline July & $\begin{array}{c}49922 \\
(11151)\end{array}$ & $\begin{array}{c}54675^{* * *} \\
(10580)\end{array}$ & +9.52 & $\begin{array}{c}48732 \\
(10591)\end{array}$ & -2.38 & $\begin{array}{c}50525 \\
(10495)\end{array}$ & +1.21 \\
\hline August & $\begin{array}{c}50542 \\
(10406)\end{array}$ & $\begin{array}{c}64556^{* * *} \\
(12095)\end{array}$ & +27.73 & $\begin{array}{c}70131^{* * *} \\
(12834)\end{array}$ & +38.76 & $\begin{array}{c}57997^{* * *} \\
(12363)\end{array}$ & +14.75 \\
\hline September ${ }^{a}$ & $\begin{array}{c}8993 \\
(3502)\end{array}$ & $\begin{array}{c}12272^{* * *} \\
(3960)\end{array}$ & +36.46 & $\begin{array}{c}12008^{* * *} \\
(3989)\end{array}$ & +33.53 & $\begin{array}{c}10516^{* * *} \\
(3491)\end{array}$ & +16.94 \\
\hline
\end{tabular}

mate change is not expected to increase the variability of monthly and annual numbers of visitors. In contrast, even a significantly lower dispersion of lido visitors in May (for both lidos) is found for the A1B and A2 scenarios. Thus, more stable (and higher) visitor flows are indicated for the beginning of the lido season in May.

\section{DISCUSSION}

Our analysis is based on 2 lidos at Lake Zurich. Future investigations on the climate sensitivity of outdoor recreation should focus on different types of lidos (e.g. also focus on lidos that are only based on swimming pools) as well as at different locations (e.g. lidos at different lakes) to allow for more general conclusions. To investigate the weather sensitivity of lido visitor flows on a more general level, competing locations and activities should be explicitly considered. To this end, regression systems could be used that explain weather influence and the cross-correlation between competing locations and activities jointly.
From a policy perspective, such analysis could provide integrated assessment tools that can be used for sensitivity analyses.

We assumed constant boundary conditions with regard to lido equipment and capacity as well as with regard to price levels and competing swimming and outdoor recreation opportunities. Despite smaller maintenance and renovation works, no large changes in lido equipment and capacity took place in the study period. Prices did increase over time, though not clearly separable because prices for different visitor classes (children, adolescents, adults) changed separately ${ }^{9}$. Over the entire 2003-2010 period, these price increases were in the range of 17 to $20 \%$. Because we have no information on the composition of our entry data with respect to these groups, no explicit link can be made to price changes. However, we expect that these price increases are normal, as wages and prices for other goods and recreation sites

\footnotetext{
${ }^{9}$ Information on lidos and pricing were taken from the website of the sports department of the City of Zurich (www. stadt-zuerich.ch)
} 
increased in this period. Furthermore, the population in the city of Zurich also increased in these years and other potential determinants of lido visiting may have changed. Therefore, it is not possible to separate these effects directly in regression models. However, we expect that these developments were captured in the trend variable employed in our analysis.

In future research, however, price effects should be considered, because admission prices could be a valuable instrument for lido managers or policy makers to react to changes in (e.g. climatic) boundary conditions. More generally, the predictive capacities of the models could be improved by combining data analysis with behavioral data. Thus, revealed or stated preferences with regard to lido visiting in relation to weather conditions, entry prices and competing locations could be combined with the models.

Additional proxies or data for potential explanatory variables should be used in future research to investigate climate sensitivity of outdoor recreation. For instance, better representation of water temperatures (including likely changes in water temperatures due to climate change) could improve the results. The analysis of water temperatures should also include the increased likelihood of algal blooms and lower water quality for higher water temperatures (Hall \& Härkönen 2006). Not considering these effects might lead to an overestimation of positive climate change effects on lake tourism. Furthermore, the distribution of rainfall during a day should be explicitly represented in models explaining lido visitors, or more general outdoor recreation, which is not possible if working with weather observations on a daily basis.

Finally, the regression models may not be applicable to longer time horizons because the relationship between dependent variables and weather may change over time. For instance, visitor responses to specific weather (e.g. higher temperatures) may change if the general climatic conditions have changed. This problem does not apply for the presented near-future climate change impacts, because projected future weather conditions are still in the range of current observations (e.g. the year 2003). Longer term projections, however, would require different models to address likely changes in these relationships.

\section{CONCLUSIONS}

Analyzing the climate sensitivity of visitor flows in 2 lidos in the city of Zurich, we find that rainfall- and temperature-based variables and indicators have a strong and significant influence on the number of visitors. This finding underlines the (obvious) climatic risks in lido management. In order to cope with these risks, different strategies could be chosen by lido managers. For instance, a higher degree of flexibility with regard to the beginning and the end of the season where the lido is open (currently these days are fixed) could provide opportunities to profit from good weather conditions in spring and autumn, respectively. The high weather sensitivity of visitor flows (i.e. demand) also suggests that more flexible pricing mechanisms could lead to more continuous revenues as well as to reduce costs of unfavorable weather spells. For instance, price discounts could be used to react to cold weather events. The high weather sensitivity also indicates that insurance solutions based on weather indexes (e.g. the number of rainy days within a month) may be a promising approach to manage these climate risks and should be addressed in future research.

With regard to near-future climate change effects, our results for the period around the year 2020 show that increased spring temperatures and in particular a combination of increased temperature and reduced rainfall in autumn will lead to a significantly higher number of visitors. These results also indicate that lidos could take further advantage from climate change by expanding the opening season, which could be considered in mid-term planning of lido seasons. The potential shifts in lido seasons could also be used to adjust employee and maintenance planning.

Estimated increases of the annual lido visitor sum range from 9 to $19 \%$, depending on the emission scenario. Our analysis did not indicate increasing variability (measured at the monthly level) of visitor flows. In contrast, more stable visitor numbers are suggested for the beginning of the lido season in spring due to climate change. These estimates could be considered by lido managers and policy makers in capacity planning for the next decades. Furthermore, this indicates that the region of Lake Zurich, or Swiss lake regions in general, could benefit from an increasing lake tourism, which underlines the expectations published by the Swiss State Secretariat for Economic Affairs (SECO 2011). The results of Hamilton et al. (2005) show that Western European 'sun and beach lovers' could even stay more frequently in their home countries to spend their holidays, which could represent an opportunity for the tourism industry in Switzerland. However, a more integrated assessment is needed to analyze the questions of water, tourism and climate change, in particular if regional perspectives are investigated (Hall \& Härkönen 2006, Gössling et al. 2012). 
Acknowledgements. This paper is a contribution to the activities of the National Centre for Competence in Research (NCCR) Climate. We thank the Swiss Federal Office for Meteorology and Climatology as well as the sports department of the City of Zurich for providing access to data. Furthermore, we are grateful for comments and suggestions made by 4 anonymous reviewers on earlier drafts of the paper.

\section{LITERATURE CITED}

Berkhout PHG, Brouwer NM (2005) The influence of the weather on recreational behavior: a micro econometric approach. Tourism Anal 10:211-221

Collins M, Tett SFB, Cooper C (2001) The internal climate variability of HadCM3, a version of the Hadley Centre coupled model without flux adjustments. Clim Dyn 17: $61-81$

Dawson J, Scott D, McBoyle G (2009) Climate change analogue analysis of ski tourism in the northeastern USA. Clim Res 39:1-9

Eisenberg D, Okeke E (2009) Too cold for a jog? Weather, exercise, and socioeconomic status. Berkeley Electron J Econ Anal Pol 9:1-30

Elsasser H, Bürki R (2002) Climate change as a threat to tourism in the Alps. Clim Res 20:253-257

> Endler C, Matzarakis A (2011) Climatic and tourism related changes in the Black Forest: winter season. Int J Biometeorol 55:339-351

Finger R, Calanca P (2011) Risk management strategies to cope with climate change in grassland production: an illustrative case study for the Swiss Plateau. Reg Environ Change 11:935-949

Finger R, Lazzarotto P, Calanca P (2010) Bio-economic assessment of climate change impacts on managed grassland production. Agric Syst 103:666-674

Gordon C, Cooper C, Senior CA, Banks H and others (2000) The simulation of SST, sea ice extents and ocean heat transports in a version of the Hadley Centre coupled model without flux adjustments. Clim Dyn 16:147-168

Gössling S, Hall CM (2006) Uncertainties in predicting tourist flows under scenarios of climate change. Clim Change 79:163-173

Gössling S, Peeters P, Hall CM, Ceron JP, Dubois G, Lehmann LV, Scott D (2012) Tourism and water use: supply, demand, and security. Tour Manage 33:1-15

Greene W (2008) Functional forms for the negative binomial model for count data. Econ Lett 99:585-590

Hall CM, Härkönen T (2006) Lake tourism: an integrated approach to lacustrine tourism systems. Channelview

Editorial responsibility: Helmut Mayer, Freiburg, Germany
Press, Clevedon

Hamilton J, Maddison D, Tol RSJ (2005) Effects of climate change on international tourism. Clim Res 29:245-254

IPCC (2007) Climate change 2007: impacts, adaptation and vulnerability. Contribution of Working Group II to the Fourth Assessment Report of the Intergovernmental Panel on Climate Change. Parry ML, Canziani OF, Palutikof JP, van der Linden PJ, Hanson CE (eds) Cambridge University Press, Cambridge

> Koenig U, Abegg B (1997) Impacts of climate change on winter tourism in the Swiss Alps. J Sustain Tourism 5: 46-57

Land KC, McCall PL, Nagin DS (1996) A comparison of Poisson, negative binomial and semiparametric mixed Poisson regression models: with empirical applications to criminal careers data. Sociol Methods Res 24:387-442

Long JS (1997) Regression models for categorical and limited dependent variables. Sage Publications, London

> Moen J, Fredman P (2007) Effects of climate change on alpine skiing in Sweden. J Sustain Tourism 15:418-437

Nakicenovic N, Alcamo J, Davis G, de Vries B and others (2000) IPCC special report on emissions scenarios. Cambridge University Press, Cambridge

Nicholls S, Holecek DF, Hoh J (2008) Impact of weather variability on golfing activity and implications of climate change. Tourism Anal 13:117-130

> Palutikof JP, Agnew MD, Hoar MR (2004) Public perceptions of unusually warm weather in the UK: impacts, responses and adaptations. Clim Res 26:43-59

$>$ Perch-Nielsen S (2010) The vulnerability of beach tourism to climate change: an index approach. Clim Change 100: 579-606

> Perch-Nielsen S, Amelung B, Knutti R (2010) Future climate resources for tourism in Europe based on the daily Tourism Climatic Index. Clim Change 103:363-381

Pope V, Gallani ML, Rowntree PR, Stratton RA (2000) The impact of new physical parameterizations in the Hadley Centre climate model: HadAM3. Clim Dyn 16:123-146

Richardson RB, Loomis JB (2005) Climate change and recreation benefits in an Alpine National Park. J Leis Res 37 : $307-320$

SECO (2011) Der Schweizer Tourismus im Klimawandel, Auswirkungen und Anpassungsoptionen. State Secretariat for Economic Affairs (SECO), Bern

Semenov MA, Barrow EM (1997) Use of a stochastic weather generator in the development of climate change scenarios. Clim Change 35:397-414

Semenov MA, Brooks RJ, Barrow EM, Richardson CW (1998) Comparison of the WGEN and LARS-WG stochastic weather generators in diverse climates. Clim Res 10: 95-107

Submitted: June 23, 2011; Accepted: December 25, 2011 Proofs received from author(s): April 9, 2012 